\title{
Tone lowering in nominal compounds of Copala Triqui
}

\author{
Jamilläh Rodriguez, Lauren Clemens \\ University at Albany, State University of New York
}

\section{Introduction}

This paper examines the distribution of tone lowering in the nominal compounds of Copala Triqui (Otomanguean). We consider two types of compounds: fused compounds and unfused compounds, which differ with respect to their prosodic complexity. For both types of compounds, the second root noun lowers in some examples, while it maintains its lexically specified tone in others. In this paper, we consider the advantages and disadvantages of a lexical as compared to a structural approach to tone lowering. More specifically, tonal overlay may belong to either a categorical head or a specific syntactic configuration, as in McPherson (2014)'s description of tone overlay in the Dogon language family.

1.1 Language Background Copala Triqui is an Otomanguean language originating in rural San Juan Copala and the surrounding region in the state of Oaxaca, Mexico. It belongs to the Mixtecan branch of the family, alongside Chicahuaxtla Triqui (see DiCanio (2008)) and Itunyoso Triqui (see Matsukawa (2012); Hernández Mendoza (2017)). According to a consultant who is a certified Copala Triqui interpreter, the three varieties of Triqui are not mutually intelligible, suggesting that they are distinct languages. The Triqui varieties are also known commonly as Trique; however we use the Triqui spelling, as it is the one preferred by our consultants. Copala Triqui is known to speakers as Xna'ánj nu' and Triqui Bajo (Spanish).

Although the Copala Triqui community originated on the western border of the state of Oaxaca, many speakers have left the region due to continuous political violence and escalating economic difficulty (García Alcaraz, 1997). Today, París Pombo (2012) estimates that less than half of speakers remain in the region. More than 1,000 speakers reside in Albany, New York and others have settled on the west coast of the U.S. or in the northwestern regions of Mexico. The map in Figure 1 marks areas where Copala Triqui speakers are known to reside, although populations statistics are unreliable and many speakers are undocumented. (París Pombo, 2012; Holmes, 2013).

In many diaspora communities, speakers are choosing to speak languages other than Copala Triqui, prioritizing acculturation and social mobility over language maintenance. Children born in the U.S. are typically English-dominant with passive knowledge of Copala Triqui and Spanish. The parent generation in the U.S. is shifting from Copala Triqui to Spanish. Diaspora communities within Mexico are also shifting to Spanish, especially younger generations.

Previous work on Copala Triqui comes primarily from the documentation efforts of Barabara Hollenbach, who collected data from monolingual Copala Triqui speakers in San Juan Copala in the 1960s and 1970s. Hollenbach's extensive documentation of Copala Triqui includes work on phonology (Hollenbach, 1977, 1984), morphosyntax (Hollenbach, 1976a, 1992), the lexicon (Hollenbach, 1973b; Hollenbach \& Merino, 2009; Hollenbach, 2015), and various cultural sketches (Hollenbach, 1973a, 1995, 1998).

1.2 The data The data in this paper come from six speakers between the ages of 20 and 60 , including three women and three men. All consultants currently reside in diaspora communities; two speakers live in Oaxaca City, Mexico and four speakers live in Albany, New York. All six speakers speak Spanish to some degree, and four of the speakers are able to communicate in English.

\footnotetext{
* We would like to thank our consultants for their valuable time and for sharing their knowledge of the language: Jesús Fuentes Martínez, Javier Martínez Bautísta, Monica de Jesús Ramírez, Juana Ramírez, Rosaura Merino Ramírez, and Román Vídal López. We are also grateful to fellow linguists Lee Bickmore, George Aaron Broadwell, Christian DiCanio, Heidi Harley, Jeffrey Punske, and Nicholas Rolle.
} 


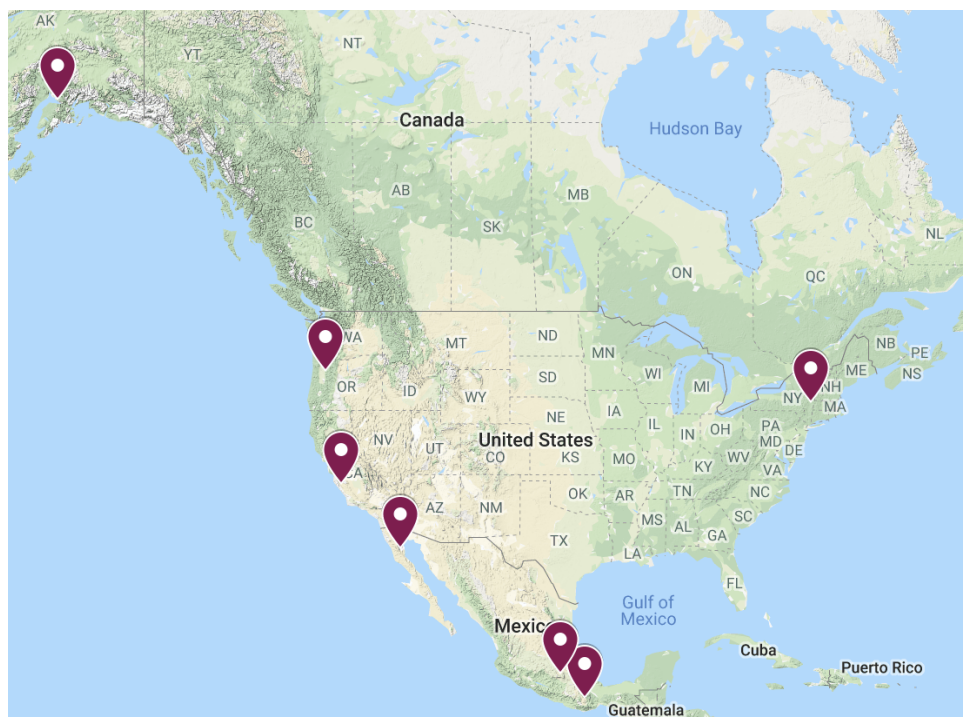

Figure 1: Distribution of Copala Triqui communities in Mexico and the U.S.

\section{Tone system of Copala Triqui}

Copala Triqui is one of the rare languages with a lexical tone system that utilizes five contrastive pitch levels (Maddieson, 1978; Longacre, 1952). There are eight lexically contrastive tones in total: five level tones $(1,2,3,4,5)$ and three contour tones $(13,31,32) .{ }^{1}$ Examples of minimal pairs illustrating the lexical contrast of tone are given in (1), (2), and (3) (Hollenbach, 1984:14).
(1) a. chruun [tșũ: $\left.{ }^{2}\right]$ 'wise'
(2) a. nee $\left[\mathrm{ne}^{3}\right]$ 'plow'
b. nee $\left[\mathrm{ne}^{31}\right]$ 'meat'
c. nee $\left[\mathrm{ne}^{32}\right]$ 'knife'
(3) a. yoó $\left[j o:{ }^{4}\right]$ 'tenate'
b. yoo [jo: $\left.{ }^{13}\right]$ 'fast'
c. yoo $\left[\mathrm{jo:}^{32}\right]$ 'cane'
b. chruun $\left[\operatorname{tsuu}^{3}\right]$ 'tree'
c. chrúún $\left[\operatorname{tsu} \tilde{u}^{5}\right]$ 'box'

The final syllable is the only place where all eight tonal contrasts are realized. Typically, tone on nonfinal syllables is predictable based on the final tone. If the tone of the final syllable begins with 3 or higher, the tone of all preceding syllables is tone 3 , as in (4). ${ }^{2}$

(4) a. rasca $\left[\mathrm{ra}^{3} \mathrm{ska}^{3}\right]$ 'sky'

b. chihá $\left[\mathrm{t}\left[\mathrm{i}^{3} \mathrm{a}^{4}\right]\right.$ 'neck'

c. anánj [anãh $\left.{ }^{5}\right]$ 'weave'

d. nacoo $\left[\mathrm{na}^{3} \mathrm{ko:}^{31}\right]$ 'dry'

e. yume $\left[\mathrm{ju}^{3} \mathrm{me}^{32}\right]$ 'sweet potato'

If the tone of the final syllable begines with 2 or lower, all preceding syllables have tone 2 , as in (5) (Hollenbach, 1984).

(5) a. yo' $\underline{0}\left[\mathrm{jo}^{2} \mathrm{Po}^{2}\right]$ 'continually'

b. cochroj $\left[\mathrm{ko}^{2} \mathrm{tsoh}^{1}\right]$ 'limping'

c. nocoo $\left[\mathrm{no}^{2} \mathrm{ko:}^{13}\right]$ 'dirty'

\footnotetext{
1 Tone 5 refers to the highest pitch and tone 1 refers to the lowest pitch level. Throughout this paper, we use superscript numbers to indicate tone in addition to the practical orthography established by Hollenbach \& Merino (2009).

2 Throughout this paper, we use the practical Copala Triqui orthography followed by the IPA transcription.
} 
There are instances of lexical items that do not adhere to this pattern. For example, in (6), the first

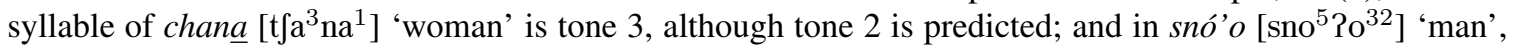
the first syllable is tone 5 , which is a tone typically reserved for final syllables.

(6) a. chana $\left[\mathrm{t} \mathrm{aa}^{3} \mathrm{na}^{1}\right]$ 'woman'

b. snó'o $\left[\mathrm{sno}^{5} \mathrm{Po}^{32}\right]$ 'man'

Throughout this paper, we only mark tone on the final syllable of a word, given that other tones are predictable, unless an example involves an exception.

Grammatically, the eight tones of Copala Triqui fall into two registers based on phonological processes such as the predictable tone rule described above. The upper register consists of tones $3,4,5,31$, and 32 . The lower register consists of tones 1,2, and 13. Typically, lexical items other than function words and adjectives have an upper register tone in isolation. However, there are many environments in Copala Triqui in which an upper register tone is lowered. The correspondence between upper register tones and lower register tones follows the paradigm presented in (7).

(7) Tonal paradigms based on Hollenbach (1984); Broadwell \& Clemens (2017)

\begin{tabular}{c|c|c|c|c|c|c|c|c} 
& Class 1 & Class 2 & Class 3a & Class 3b & Class 4a & Class 4b & Class 5a & Class 5b \\
\hline \hline Upper & 31 & 32 & 3 & 3 & 4 & 4 & 5 & 5 \\
Lower & 1 & 2 & 1 & 13 & 1 & 2 & 1 & 2
\end{tabular}

Environments in which tone lowering occurs include verbal aspect, negation, possession, appositives, predicate focus, and the derivation of adjectives and adverbs. We find that tone lowering in each these environments follows the paradigm in (7). Hollenbach (1984) reports that tone lowering in verbs follows the paradigm in (7), which she calls the 'F1 lowering rule'; however for nouns ('F2 lowering rule'), she gives three possible low tones for an upper register $3(1,13$, and 3 , i.e. no lowering) and only one lower register tone for upper register 4 and 5 (1). We have not been able to replicate this difference between nouns and verbs, and in the data that we have collected to this point, nouns behave like verbs with respect to the correspondence between upper and lower registers.

An example of tone lowering in the verbal domain comes from inflection, as shown in (8), where the non-potential aspect of the verb has an upper register tone and the potential aspect form has a lower register tone.

(8)
a. Chá Juán.
$\left[\mathrm{t} \mathrm{a}^{4} \quad\right.$ wã $\left.\tilde{a}^{4}\right]$
eat.NON.POT Juan
'Juan is eating/ate.'
b. Chạ Juán.
$\left[\mathrm{t} J \mathrm{a}^{1} \quad\right.$ wã $\left.{ }^{4}\right]$
eat.POT Juan
'Juan will eat.'

An example of Hollenbach (1984) describes as 'derivational' tone lowering is given in (9). In (9a), the preposition has an upper register tone. The adverbial form of that preposition is lowered in (9b).

(9) a. xcó quíj

$\left[\int \mathrm{ko}^{4} \mathrm{kih}^{4}\right]$

beyond mountain

'beyond the mountain'

b. chéé xco

$\left[\mathrm{t} \mathrm{ee}^{5} \mathrm{Sko}^{1}\right]$

walk beyond

'walk backwards' 
The complete tone lowering paradigm with examples from the nominal and verbal domains is given in (10). The focus of this paper is the tone lowering that occurs in nominal compounds (or the derivation of adjectives in Hollenbach 1984). Tone lowering in nominal compounds always affects the second root, never the first.

(10) Upper-lower register mapping across the nominal domain and the verbal domain

\begin{tabular}{|c|c|c|c|c|c|c|}
\hline & \multicolumn{3}{|c|}{ Nominal Domain } & \multicolumn{3}{|c|}{ Verbal Domain } \\
\hline & Simplex & Compound & Gloss & Completive & Potential & Gloss \\
\hline a. $31 \rightarrow 1$ & tachrii $^{31}$ & tachriii $^{\top}$ & 'feather' & canuu $^{31}$ & canuu $^{1}$ & 'thunder' \\
\hline b. $32 \rightarrow 2$ & rmii $^{32}$ & $\mathrm{rmii}^{2}$ & ‘ball’' & $\operatorname{cotoj}^{32}$ & $\operatorname{cotoj}^{2}$ & ‘sleep' \\
\hline c. $3 \rightarrow 1$ & yu've'3 & yu've' ${ }^{1}$ & 'snow' & cavi' $^{3}$ & 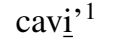 & 'die’' \\
\hline d. $3 \rightarrow 13$ & $\mathrm{aga}^{3}$ & agga $^{\prime 13}$ & ‘iron’ & $\operatorname{caraa}^{3}$ & $\operatorname{caraa}^{13}$ & 'fill' \\
\hline e. $4 \rightarrow 2$ & agüeé ${ }^{4}$ & agüee $^{2}$ & 'coffee' & cachén ${ }^{4}$ & cachen $^{2}$ & 'pass' \\
\hline f. $5 \rightarrow 1$ & cúú $^{5}$ & cuj $j^{1}$ & 'bone' & $\mathrm{sij}^{5}$ & $\mathrm{sij}^{1}$ & 'massage' \\
\hline g. $5 \rightarrow 2$ & chrúún ${ }^{5}$ & chrunjij $^{2}$ & 'oven' & náán ${ }^{5}$ & naan $^{2}$ & ‘wash’ \\
\hline
\end{tabular}

\section{Nominal compound constructions}

Copala Triqui has four different types of nominal compounds that vary along two dimensions: degree of phonological merger and tone register, as illustrated in Figure 2. We use the terms 'fused compound' and 'unfused compound' to refer to the degree of phonological merger of the two root nouns, following an analysis of compounds in Chicahuaxtla Triqui by Hernández Mendoza (2014). Fused compounds are comprised of one complex prosodic- $\omega$, while unfused compounds consist of two simplex prosodic- $\omega s$. Nominal compounds also differ in tone register; both fused and unfused compounds sometimes appear with a lower register tone and sometimes appear with an upper register tone, as discussed in $\S 3.1$ and $\S 3.2$, respectively.

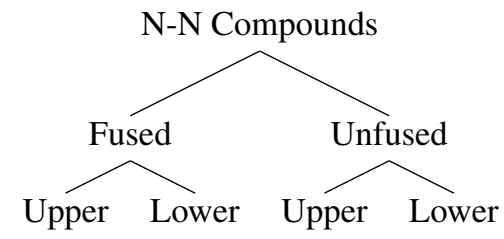

Figure 2: Dimensions of variation in nominal compounds of Copala Triqui

According to Hollenbach (2008), the difference between fused and unfused compounds is time depth; older compounds have become 'fused' over time. Despite this difference, on her account, both fused and unfused compounds are lexicalized: compounds without tone lowering are lexicalized N-N compounds, and compounds with tone lowering are lexicalized $\mathrm{N}$-A compounds where the adjective is denominalized through the tone lowering process itself, which takes place in the lexicon.

The evidence that Hollenbach $(1984,2008)$ gives for lexicalization is that the compounding process is not productive and that the meaning of the resulting compound is figurative. However, our consultants accept and easily assign meaning to tone lowering on novel forms, suggesting that the process is in fact productive. Furthermore the same nominal compound can have both a literal and a figurative translation, as shown in (11).

$$
\begin{aligned}
& \text { nana catuun /catuun/ } \\
& {\left[\mathrm{na}^{3} \mathrm{na}^{1} \text { katũ: }{ }^{1}\right] / \text { katũ: }^{31} /} \\
& \text { wind waist } \\
& \text { 'thin voice; smooth wind' }
\end{aligned}
$$

Note that catuun [katũ:is ] 'thin, lit.: waist' is used to describe thin individuals as well. 
3.1 Fused compounds Simplex prosodic- $\omega$ compounds, or "fused compounds" (Hernández Mendoza, 2014), involve the loss of a word boundary (Hollenbach, 1984) ${ }^{3}$. These compounds are always head-initial, consisting of a noun followed by a modifier. They behave like single prosodic- $\omega$ s with respect to Triquispecific criteria. In the lexicon at large, all non-final syllables are $\mathrm{CV}$, a property which is maintained in fused compounds. (See Hernández Mendoza $(2014,2017)$ for a similar process occuring in Chicahuaxtla Triqui.)

$$
\begin{aligned}
& \text { a. } \quad\left[\mathrm{ra}^{3} \cdot \tilde{\mathrm{u}}^{2}\right] \quad / \mathrm{raPa}^{3} \mathrm{zu}^{2} / \\
& \text { hand.work } \\
& \text { 'thing' } \\
& \text { b. }\left[\mathrm{ka}^{3} \cdot \mathrm{nuj}^{13}\right] / \mathrm{kãj}^{3} \mathrm{nuj}^{13} / \\
& \text { sandal.skin } \\
& \text { 'shoe' }
\end{aligned}
$$

(Hernández Mendoza, 2014:14)

Fused compounds demonstrate a greater range of behavior with respect to conforming to Copala Triqui tonotactics, as illustrated in (13). In example (13a) taga $\left[\mathrm{ta}^{3} \mathrm{ga}^{3}\right]$ 'jail', a fused compound of to'cuá [to?kwa $\left.{ }^{4}\right]$ 'house' and $a g a$ ' $\left[\mathrm{agaP}^{3}{ }^{3}\right.$ ' 'metal', the first syllable follows the default tone rule described in $\S 2$. Because the final syllable $g a$ has a tone 3, the previous syllable has tone 3 . In contrast, the fused compound in (13b) maintains the lexical tone of the first syllable. Yá'nuj $\left[j a P^{5}{ }^{5} \mathrm{~h}^{13}\right]$ 'drum', a fused compound of $y a$ 'ánj ${ }^{5}$ [ja?ãh $\left.{ }^{5}\right]$ 'instrument' and $n u j^{3}\left[\right.$ nuh $\left.^{3}\right]$ 'skin', does not follow the default tone rule, which would mean a tone 2 on the first syllable because the tone of the final syllable is tone 13. Instead, the lexically contrastive tone from the root, tone 5 , is maintained in the compound.

$$
\begin{aligned}
& \text { a. ta.ga /to'cuá aga'/ } \\
& {\left[\mathrm{ta}^{3} \cdot \mathrm{ga}^{3}\right] \quad / \text { torkwa }^{4} \mathrm{aga?}^{3} /} \\
& \text { house.metal } \\
& \text { 'jail' } \\
& \text { b. yá.nuj /ya'ánj nuj/ } \\
& {\left[\mathrm{ja}^{5} \cdot \text { nuh }^{13}\right] \text {. ja?ãh }{ }^{5} \text { nuh }^{3} /} \\
& \text { instrument.skin } \\
& \text { 'drum' }
\end{aligned}
$$

Also note that the tone of the second root is lowered in some cases, but not in all cases. In (13a), the tone of the second root $\mathrm{aga}^{3}{ }^{3} \mathrm{aga}^{3}$ ] 'metal' is the same in isolation as it is in the compound form, but in (13b) the tone on $n u j^{3}\left[\mathrm{nuh}^{3}\right]$ 'skin' is lowered to $n u j^{13}\left[\mathrm{nuh}^{13}\right]$ in the compound form. The lowering follows the paradigm in 7 , where lexical items belonging to Class $3 \mathrm{~b}$ with tone 3 are lowered to tone 13 .

Fused compounds do appear to be limited to existing forms. Our consultants do not appear to use this type of compounding productively, but they do have a productive use of the unfused compounding described in the next section.

3.2 Unfused compounds In contrast to fused compounds, unfused compounds consist of two roots that each behave like an individual prosodic- $\omega$. The individual roots independently conform to Triqui phonotactics and tonotactics, but the compound as a whole does not. Like fused compounds, the tone of the second root lowers in some cases, but not in all. In both of the examples in (14), the second root of the compound is $y a^{\prime} a j$ $\left[\mathrm{ja} P a h^{3}\right]$ 'chili', which surfaces as $y a^{\prime}{ }^{\prime} j\left[\mathrm{ja} \mathrm{ah}^{1}\right]$ in (14a), but as $y a^{\prime} a j\left[\mathrm{ja} \mathrm{ah}^{3}\right]$ in (14b).

$$
\begin{aligned}
& \text { a. coj ya'aj /ya'aj/ } \\
& {\left[\mathrm{koh}^{32} \mathrm{jaPah}^{1}\right] / \mathrm{jaPah}^{3} /} \\
& \text { plant chili } \\
& \text { 'chili plant' }
\end{aligned}
$$

\footnotetext{
3 We mark syllable boundaries in the fused compounds given in (12) and (13) to show that each syllable is taken from a separate root.
} 
b. scaan ya'aj /ya'aj/

[skã:i $\left.{ }^{32} \mathrm{jaPah}^{3}\right] / \mathrm{jaPah}^{3} /$

seed chili

'chili seed'

As is clear from the examples in (14), properties inherent to the modifying root do not determine whether the tone of the modifying root lowers. Similarly, properties inherent to the head noun, do not determine whether the modifying root lowers. In (15), both compounds have $v e$ ' $\left[\beta \mathrm{e}^{3}\right]$ 'house' as the head, but in (15a) the modifying root $c \underline{u j}{ }^{1}{ }^{1}\left[\mathrm{kuh}^{1}\right]$ 'bone' is lowered from an upper register tone 5 to the lower register tone 1 . In contrast, the modifying root in (15b), yij [jih ${ }^{3}$ ] 'stone', maintains its lexical tone 3 in the compound form.
a. ve' cujj /cúú/
$\left[\beta \mathrm{e}^{3} \mathrm{kuh}^{1}\right] / \mathrm{ku}^{5} /$
house bone
'clean house'
b. ve' yij $/ y i j /$
$\left[\beta \mathrm{e}^{3} \mathrm{jih}^{3}\right] / \mathrm{jih}^{3} /$
house stone
'stone house'

In fact, as shown in the examples of (16), it is possible to use a single root, here yo'ó [yo' o: ${ }^{5}$ ] 'dirt', to exemplify i) a head that combines with a modifier that lowers (16a), ii) a head that combines with a modifier that surfaces in its upper register form (16b), iii) a modifier that lowers (16c), and iv) a modifier that surfaces in its upper register form (16d).

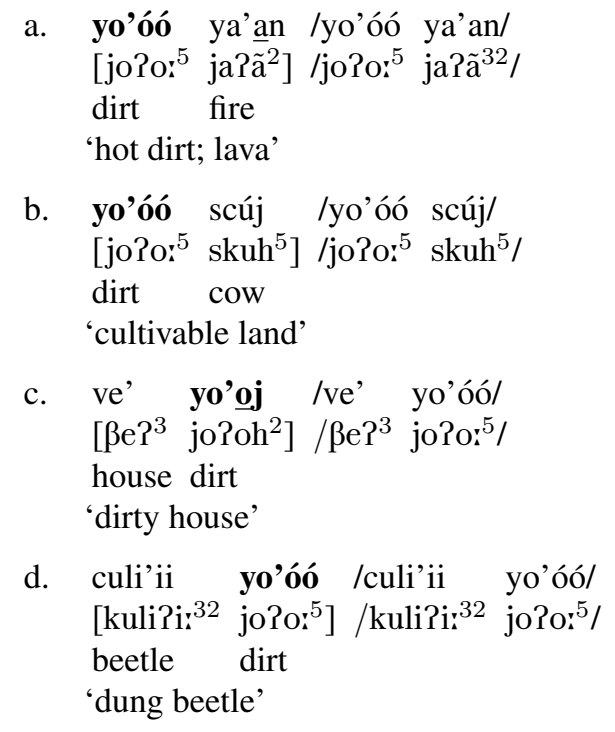

In sum, we find two types of nominal compounds, 'fused' and 'unfused', that differ with respect to their internal structure: fused compounds behave as a single prosodic- $\omega$ with respect to Copala Triqui-specific phonotactics, while unfused compounds do not. Fused compounds are a closed class of items (Hollenbach 1984), whereas we find that the process resulting in unfused compounds is productive to some extent. Finally, we have seen examples of both fused and unfused compounds that display tone lowering on the second root and examples of those for which each root surfaces with its isolation tone.

\section{Tone lowering phonology of nominal compounds}

In this section, we examine the phonology of tone lowering in nominal compounds. The tone lowering seen in nominal compounds of Copala Triqui is not tone sandhi, as tone lowering is not influenced by the tone 
of the preceding root. For example, rmii [smii ${ }^{32}$ ] 'ball', lexically a tone 32 , lowers to tone 2 in both (17a) and (18), where it is the second root in the compound following a lexical tone 4 and 32 , respectively. Thus, the tone of the first root noun does not affect the lowering of the second root noun.
a. manzaná rmii /rmii/
$\left[\right.$ mansana $\left.{ }^{4} \mathrm{smi}^{2}\right] / \mathrm{smi}^{32} /$
apple ball
'round apple'
b. ra'vii rmii /rmii/
$\left[\mathrm{raPBi} \mathrm{i}^{32}\right.$
apple orange
'round orange'

An example of a compound with lowering is given in Figure 3, which shows the root cúú $/ \mathrm{ku}^{5} /$ ' bone' in two contexts: as $\mathrm{N}_{1}$ and as $\mathrm{N}_{3}$ in the nominal compound presented in (18).

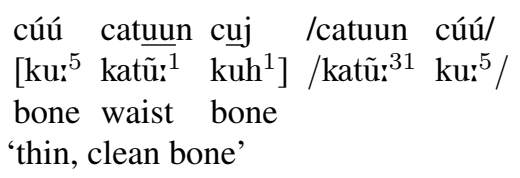

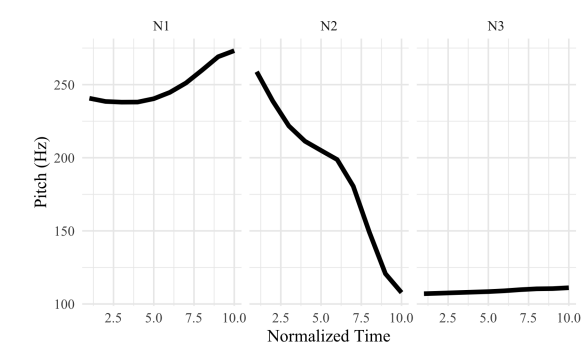

(a) Pitch track for cúú catuun cuj /ku:5 katũu: ${ }^{31}$ $\mathrm{ku}^{5} /$ 'thin clean bone'

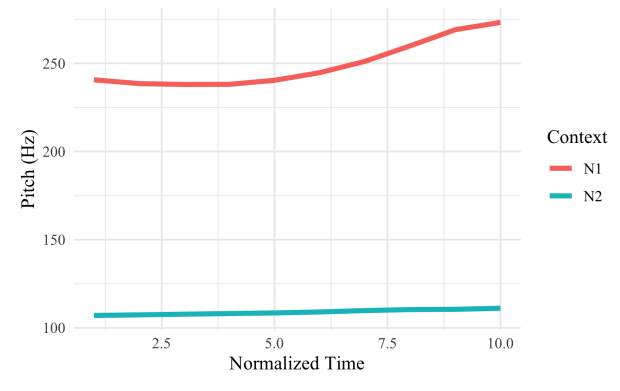

(b) Pitch track comparison of cúú $/ \mathrm{ku}^{5} /$ and $/ \mathrm{kuh}^{1} /$ 'bone'

Figure 3: Pitch tracks of cúú /ku: $/ 5$ 'bone' in two contexts: $\mathrm{N}_{1}$ and $\mathrm{N}_{3}$

The mapping between the upper register form and the lower register form is not entirely predictable. As shown in the register paradigm in Figure 7 discussed above, lexical items with an upper register tone of 3, 4, or 5 have two possible lower register tones. Example (19) shows that roots with a lexically specified tone 3 can lower to either tone 1 or tone 13. In (19a), yu've' [ju?ße ${ }^{1}$ ] 'snow' has a lexical tone 3, but surfaces as tone 1 in the position of second root noun. In contrast, aga' [aga ${ }^{3}$ ] 'metal' surfaces as 13 when it is a second root noun in a compound, as in (19b).
a. tacaan yu've' /yu've'/
$\left[\operatorname{takãa}^{3} \quad\right.$ ju$\left.^{2} \beta \mathrm{e}{ }^{1}\right] /$ ju?ße? $^{3} /$
mountain snow
'snowy mountain'
b. mesá aga ' /aga'/
$\left[\mathrm{mesa}^{4} \mathrm{aga?}^{13}\right] / \mathrm{agar}^{3} /$
table metal
'iron table'

If a given root lowers to 1 or 13 in some context, it always lowers to 1 or 13 , i.e. it is not the case that sometimes a single root lowers to 1 and other times it lowers to 13 . 
Tone lowering in Copala Triqui is also not the result of the docking of a floating tone. While floating tones tend to be concatenative, these lower register tones are completely replacive. Tone lowering in these compounds is best understood as a low tone overlay, similar to the tone overlay discussed in McPherson (2014)'s analyis of tone lowering in the Dogon language family.

A tone overlay is a tone or tone sequence that completely replaces the lexical tone of a word or phrase in specific morphosyntactic contexts McPherson (2014). An example from Najamba, a Dogon language of Mali, is given in (20). The definite and demonstrative have the same form mó, but 'sheep' with an underlying form of /pغ̀gé/ only receives a low replacive tone overlay when preceding the demonstrative.

$$
\begin{aligned}
& \text { a. pègé mó /pغ̀gé/ } \\
& \text { sheep DEF } \\
& \text { 'the sheep' } \\
& \text { b. pègè mó /pègél } \\
& \text { sheep that } \\
& \text { 'that sheep' }
\end{aligned}
$$

(Heath, 2017:102)

In sum, we have seen that tone lowering in Copala Triqui is not influenced by neighboring tones and that the mapping between higher and lower register tones is not entirely predictable. Furthermore, as tone lowering is completely replacive, it does not lend itself to a floating tone analysis. Thus, tone lowering in Copala Triqui is best thought of as a tone overlay.

Several questions about the phonology of tone lowering in Copala Triqui's nominal compounds remain unanswered. First, it is unclear how to account for the variable behavior of the tone of the first syllable in fused compounds. Recall that in a subset of fused compounds, the tone of the first syllable follows Copala Triqui's default tone assignment rule, which is to assign tone 2 to the syllables preceding a lower register tone, and tone 3 to the syllables preceding an upper register tone. In other cases, the tone of the first root maintains its lexically contrastive tone, disobeying the default tone assignment rule. We leave this question unanswered, turning instead to consider tone lowering and the difference between fused and unfused compounds from a morphosyntactic perspective.

\section{Towards an analysis}

In this section, we compare two ways of accounting for fused vs. unfused nominal compounds in Copala Triqui (with and without tone lowering), which we label i) the categorical approach and ii) the structural approach. In the categorical approach the presence of an $a^{0}$ head triggers tone overlay. In the structural approach the overlay occur in specific syntactic configurations.

5.1 Categorial approach Perhaps the most straightforward analysis is one in which tone lowering on roots is the result of a compound formed with a noun and an adjective. Caching out this approach in the terms of Distributed Morphology (Halle \& Marantz, 1993, 1994; Harley \& Noyer, 2003; Embick \& Noyer, 2007; Harley, 2009), an acategorial root merges with an $a^{0}$ head, which triggers the tonal overlay on the root.

The question then becomes how to account for the difference between the fused and unfused compounds, which seem to differ in their degree of integration. Fused compounds, as in (21), are formed when $\mathrm{a}^{0}$ and the root undergo m-merger, which in turn, undergoes m-merger with the root it modifies (see Siddiqi (2009) on primary compounds). ${ }^{4}$

4 Note that a more detailed analysis would need to include a mapping constraint for mapping word-internal XPs onto a prosodic- $\omega$, causing truncation and in some cases initial- $\sigma$ default tone in the case of the fused compounds. 
(21) Fused compound with lowering: yá.nuj $\left[\mathrm{ja}^{5} \cdot \mathrm{nuh}^{13}\right] / \mathrm{ya} \mathrm{anj}^{5} \mathrm{nuj}^{3} /$ 'drum' (Lit. instrument skin)

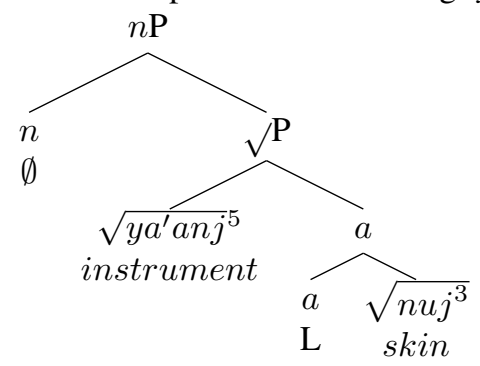

This type of approach follows Hollenbach (2008) closely, who describes nominal compounds in Copala Triqui as lexicalized N-A compounds, where the adjective is denominalized through tone lowering that takes place in the lexicon.

The derivation of compounds without tone overlay would precede in much the same way; the primary difference is the category associated with the modifying root. When an acategorial root merges with $n^{0}$, tone overlay does not apply. This is shown in (22).

Fused compound without lowering: taga $\left[\mathrm{ta}^{3} \mathrm{ga}^{3}\right]$ /to'cuá aga'/ 'jail' (Lit. house metal)

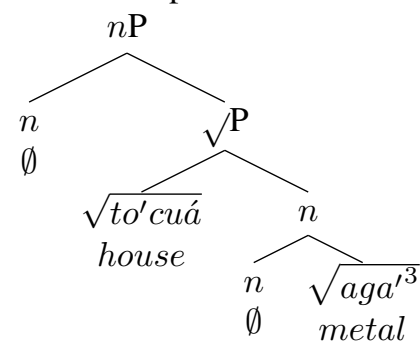

Turning to unfused compounds and beginning with those that display tone overlay, here, a phrasal category $-a \mathrm{P}$ - modifies the head noun (see also Harley 2009). Because the modifier is phrasal, the modifying root does not go onto merge with the head noun, and as such no 'fusion' occurs. This is shown in (23) where it is still assumed that the presence of $a^{0}$ is the trigger of the tone overlay.

(23) Unfused compound with lowering: ve' $c \underline{j} j\left[\beta \mathrm{e}^{3} \mathrm{kuh}^{1}\right] / \mathrm{ve}^{3}$ cúú ${ }^{5} /$ 'clean house'

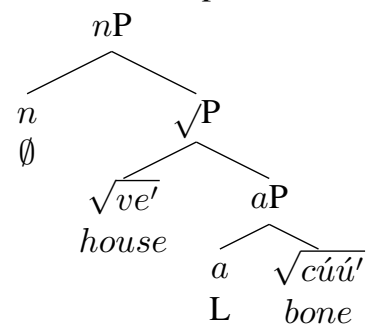

Similarly, in an unfused compound without tone overlay, modification of the head noun is phrasal, but here the category is nominal instead of adjectival, and so the head associated with tone overlay does not enter the derivation. This is illustrated in (24):

(24) Unfused compound without lowering: chraa aga' [ tsa: $:^{3}$ aga $\left.{ }^{3}\right] /$ chraa aga'/ 'cymbal'

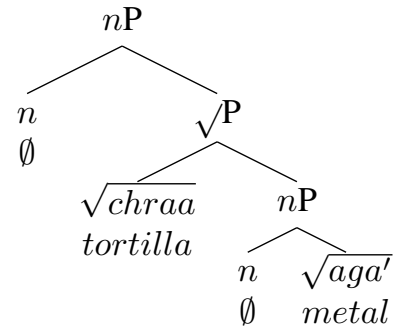


In sum, on a categorial approach, the size of the modifier $\left(\mathrm{X}^{0}\right.$ or $\left.\mathrm{XP}\right)$ determines whether the compound is fused or not, while the category the modifying root combines with $\left(a^{0}\right.$ or $\left.n^{0}\right)$ determines whether or not tone lowering occurs.

This type of account makes the following basic prediction: if adjectives are derived by combining an acategorial root with an $a^{0}$, then these roots with a low tone overlay should behave like adjectives in other contexts. One problematic data point comes from tripartite compounds. Examples of tripartite compounds are shown in (25). All of our examples of tripartite compounds occur with a tone overlay:

$$
\begin{aligned}
& \text { a. chii yu've' yo'oj /yu've' yo'óó/ } \\
& {\left[\mathrm{t} \mathrm{ir}_{\mathrm{i}}^{3} \text { ju?ße? }^{1} \text { jo?o: }^{1}\right] / \mathrm{ju} \beta \mathrm{e}^{3} \text { jo?o: }^{5} /} \\
& \text { man snow dirt } \\
& \text { 'dirty snowman' }
\end{aligned}
$$

b. ve' chruun cụj/chruun cúú/

$$
\begin{aligned}
& {\left[\beta \mathrm{e} \mathrm{P}^{3} \text { tsũ }^{1}{ }^{1} \mathrm{kuh}^{1}\right] / \mathrm{tsc}_{\mathrm{s}}^{3} \quad \mathrm{ku}^{5} /} \\
& \text { house tree bone } \\
& \text { 'clean wooden house' }
\end{aligned}
$$

While tripartite compounds forms exist, they represent the upper limit in compound size. Interestingly, more than two root adjectives can modify a single noun. Examples of root adjectives include color terms, size adjectives and certain adjectives of subjective measure, e.g. chihan' [ $\left.\mathrm{t} \mathrm{i} \mathrm{a}^{1}\right]$ 'delicious' and niha' [nia? ${ }^{1}$ ] 'happy', as in 26. Note that while root adjectives have an underlying low register tone, they do not obviously correspond to any upper register nominals.

$$
\begin{aligned}
& \text { a. coj maree le'ej chihan' } \\
& {\left[\mathrm{koh}^{32} \text { mare: }^{31} \text { le?eh }{ }^{13} \text { tfiã }{ }^{\overline{1}}\right]} \\
& \text { plant green small delicious } \\
& \text { 'small, delicious, green plant' } \\
& \text { b. xnii xcaan manj nihạ rá } \\
& \text { [ } \left.\int \mathrm{ni}^{3}{ }^{3} \int \mathrm{ka \tilde {i }}{ }^{1} \text { mãhh }^{2} \text { nia }^{1} \mathrm{ra}^{4}\right] \\
& \text { boy tall fat happy PART } \\
& \text { 'happy, fat, tall child' }
\end{aligned}
$$

The problem, then, is that if tone lowering in compound nouns is connected to the presence of an $a^{0}$, the process does not quite render an adjective. More specifically, if $c \underline{u j}\left[\mathrm{kuh}^{1}\right]$ in $(25 \mathrm{~b})$ and $l e^{\prime} e j\left[\mathrm{le}^{\mathrm{e}} \mathrm{eh}^{13}\right]$ in (26a) are both adjectives, there would be no way to account for the contrast between the maximally tripartite forms with two modifying roots in 25 and the phrases with three adjectives in 26. A structural approach, while not without its own challenges, does allow us to account for this difference.

5.2 Structural approach Here we sketch an alternative to the categorial approach, which we refer to as the structural approach. The goal of this style of analysis is to identify structural differences between compounds with and without tone overlay. We take as our jumping off point that there is more structure in examples with tone overlay as compared to those with citation tone. For the time being we leave the difference between fused and unfused compounds aside.

On this type of account, we would treat citation tone compounds as root compounds derived via mmerger (Siddiqi, 2009). An example is shown in (27).

(27) a. Unfused compound without lowering: chraa aga' [ tsa: $\left.^{3} \mathrm{aga}^{3}\right] /$ chraa aga'/ 'cymbal'

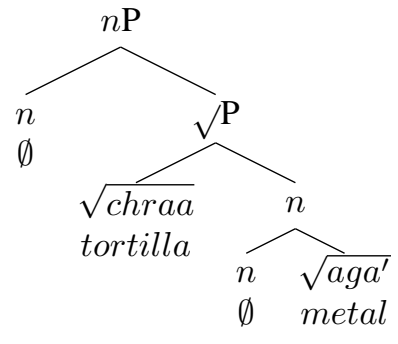


In contrast, compounds with tone overlay can be represented via phrasal modification (Harley, 2009). The generalization would be that when a root combines with a phrase, as opposed to a head, the modifying phrase is produced with the lower register tone. This type of analysis is illustrated in (28):

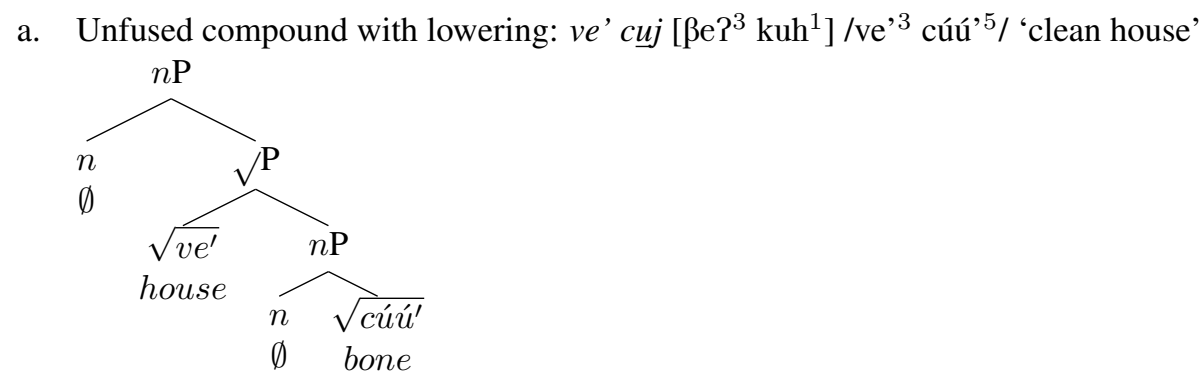

For this style of account the tonal overlay would not be associated with a specific head, but with a specific configuration: when a root (as opposed to a category head) combines with a phrase, the modifying phrase is produced with the low register tone. The primary benefit of this type of account would be that it has the potential to unite all of the different environments where tone lowering takes place, many of which were introduced in Section 2.

A second positive outcome is that a structural approach easily accounts for the upper limit in compound size (two modifying roots) as compared to the maximum size of noun phrases modified by root adjectives (three and more), as discussed in Section 5.1. On this account, compounding and adjectival modification are fundamentally different processes.

A challenge for the structural account comes from the difference between fused and unfused compounds. There are two avenues for solving this problem, which we leave for future work. First, fusion might result from the incorporation of the head and modifier, i.e. the $n \mathrm{P}$ phrase or $n$ depending on whether the form displays tone overlay or not. Second, because the set of fused compounds is fairly small, whether or not the modifier incorporates may well be a lexically-specified property of compound heads.

\section{Conclusion}

To conclude, we have presented four types of nominal compounds that differ on two dimensions: i) the degree of phonological merger, i.e. whether the compound behaves as a single prosodic- $\omega$ or a complex prosodic- $\omega$ and ii) whether or not the second sub-constituent of the compound has a low tone overlay. The distinction between the four compound types discussed in this paper are presented in 29 below.

Examples of four types of Copala Triqui compounds

\begin{tabular}{c|c|c} 
& Fused & Unfused \\
\hline \hline \multirow{2}{*}{ Upper } & taga $\left[\mathrm{ta}^{3} \cdot \mathrm{ga}^{3}\right]$ & yo'óó scúj $\left[\mathrm{jo} \mathrm{jo}^{5} \mathrm{skuh}^{5}\right]$ \\
& 'jail' (lit: metal house) & 'cultivable land' (lit: dirt cow) \\
Lower & yánuj $\left[\mathrm{ja}^{5} \cdot \mathrm{nuh}^{13}\right]$ & ve' cuj $\left[\beta \mathrm{eP}^{3} \mathrm{kuh}^{1}\right]$ \\
& 'drum' (lit: instrument skin) & 'clean house' (lit: house bone)
\end{tabular}

In analysing Copala Triqui's nominal compounds we considered two central questions. First, where in the grammar is the process of compounding located: lexical or structural? Second, what is the nature of the tonal overlay? Does it belong to a categorial head or is it the result of a particular syntactic configuration?

Finally, we sketched the beginning of an analysis in which tone lowering represents a tonal overlay required when a root is modified by an XP as opposed to an $\mathrm{X}^{0}$. The primary benefit of this type of analysis would be to leave open the possibility that tone lowering across the grammar of Copala Triqui is not distinct, but rather, triggered by a single configuration. Differences between unfused compounds with and without lowering as well as the fact that roots with the lower register overlay do not quite behave like adjectives supports this analysis. The challenge becomes distinguishing fused and unfused compounds, which we leave to future work. 


\section{References}

Broadwell, George Aaron \& Lauren Clemens (2017). Inflectional change in Copala Triqui.

DiCanio, Christian (2008). The Phonetics and Phonology of San Martín Itunyoso Trique. Ph.D. thesis, University of California, Berkeley.

Embick, David \& Rolf Noyer (2007). Distributed morphology and the syntax/morphology interface. Ramchand, Gillian \& Charles Reiss (eds.), The Oxford Handbook of Linguistic Interfaces, Oxford University Press, Oxford.

García Alcaraz, Agustín (1997). Tinujei: Los triquis de Copala. Centro de Investigaciones y Estudios Superiores en Antropología Social.

Halle, Morris \& Alec Marantz (1993). Distributed morphology and the pieces of inflection. Lieber, Rochelle \& Pavol Stekauer (eds.), The view from Building 20: Essays in linguistics in honor of Sylvain Bromberger, MIT Press, Cambridge, MA, 111-176.

Halle, Morris \& Alec Marantz (1994). Some key features of Distributed Morphology. MIT Working Papers in Linguistics 21, MIT Press, Cambridge, MA.

Harley, Heidi (2009). Compounding in distributed morphology. Lieber, Rochelle \& Pavol $\backslash \mathrm{v}\{\mathrm{S}\}$ tekauer (eds.), The Oxford Handbook of Compounding, Oxford University Press, Oxford.

Harley, Heidi \& Rolf Noyer (2003). Distributed Morphology. Cheng, Lisa \& Rint Sybesma (eds.), The Second Glot International State-of-the-Article Book, Mouton de Gruyter, Berlin.

Heath, Jeffrey (2017). A Grammar of Najamba.

Hernández Mendoza, Fidel (2014). Prominencia Silábica en el Triqui de Chicahuaxtla. Proceedings of the Workshop on the Sound Systems of Mexico and Central America, Yale University, URL https://ling.yale.edu/ssmca-proceedings.

Hernández Mendoza, Fidel (2017). Tono y fonología segmental en el triqui de Chicahuaxtla. Ph.D. thesis, Universidad Nacional Autónoma de Mexico, Yale University.

Hollenbach, Barbara (1973a). El parentesco entre los triques de Copala, Oaxaca. América Indígena 33, 167-186.

Hollenbach, Barbara (1973b). La aculturación linguística entre los triques de Copala, Oaxaca. América Indígena 33, $65-95$.

Hollenbach, Barbara (1974). Reduplication and anomalous rule ordering in Copala Trique. International Journal of American Linguistics 40, 176-181.

Hollenbach, Barbara (1976a). Tense-negation interplay in Copala Trique. International Journal of American Linguistics 42, 126-132.

Hollenbach, Barbara (1976b). Two Copala Trique adverbs for much. International Journal of American Linguistics 42, 164-165.

Hollenbach, Barbara (1977). Reversal of Copala Trique temporal metaphors through language contact. International Journal of American Linguistics 43, 150-154.

Hollenbach, Barbara (1980). El mundo animal en el folklore de los triques de Copala. Tlalocan 8, 437-490.

Hollenbach, Barbara (1984). The phonology and morphology of tone and laryngeals in Copala Trique. Ph.D., University of Arizona.

Hollenbach, Barbara (1990). Semantic and syntactic extensions of Copala Trique Body-Part Nouns. Garza Cuarón, Beatriz \& Paulette Levy (eds.), Homenaje a Jorge Suárez, El Colegio de México, 275-296.

Hollenbach, Barbara (1992). A syntactic sketch of Copala Trique. Bradley, C. Henry \& Barbara Hollenbach (eds.), Studies in the syntax of Mixtecan languages, Summer Institute of Linguistics and the University of Texas at Arlington, Dallas, Texas, vol. 4, 173-431.

Hollenbach, Barbara (1995). Tres temas dominantes en la cultura triqui. Schobinger, Juan (ed.), Humanismo siglo XX: Estudios dedicados al Dr. Juan Adolfo Vázquez, Editorial Fundación Universidad Nacional de San Juan, San Juan, Argentina, 129-34.

Hollenbach, Barbara (1998). A cultural sketch of the Copala Trique. URL http://www.sil.org/mexico/mixteca/triqui-copala/A001-Culturalsketch-TRC.htm.

Hollenbach, Barbara (2008). Gramática popular del triqui de Copala. Instituto Lingüístico de Verano, A.C.

Hollenbach, Barbara (2015). Diccionario triqui-español y español-triqui; Triqui de San Juan Copala. URL http: / / www.barbaraelenahollenbach.com.

Hollenbach, Barbara \& Miguel Santillán Merino (2009). Letrá achrón ní’ xna’ánj nu’ a: El alfabeto del triqui de Copala. Instituto Lingüístico de Verano .

Holmes, Seth (2013). Fresh Fruit, Broken Bodies: Migrant Farmworkers in the United States. University of California Press.

Longacre, Robert (1952). Five phonemic pitch levels in Trique. Acta linguistica 7:1-2, 62-82.

Maddieson, Ian (1978). Universals of tone. Greenberg, J. H. (ed.), Universals of Human Language; Volume 2 Phonology, Stanford University Press, Stanford, 335-363.

Matsukawa, Kosuke (2012). Phonetics and Phonology of Chicahuaxtla Triqui Tones. Ph.D. thesis, University at Albany.

McPherson, Laura (2014). Replacive grammatical tone in the Dogon languages. Ph.D. thesis, University of California, Los Angeles.

París Pombo, María Dolores (2012). Diáspora Triqui: Violencia política, desplazamiento forzado y migración. Universidad Autónoma Metropolitana.

Siddiqi, Daniel (2009). Syntax within the word: Economy, allomorphy, and argument selection in Distributed Morphology. John Benjamins Publishing Company. 